\title{
An Open Model to Define Adaptive Educational Hypermedia Systems Based on Learning Technology Specifications
}

\author{
Adriana Berlanga, Francisco García \\ University of Salamanca \\ solis13@usal.es,fgarcia@usal.es
}

\begin{abstract}
This paper outlines an ongoing research focus on the definition of an open model to authoring adaptive educational hypermedia systems. The goal is to make it possible to design adaptive environments for any knowledge field, educational level, instructional design or learning style as well as giving the teachers the possibility of creating their own adaptive rules. Moreover, standardized metadata, namely IMS, is used to define the semantic of the elements and guarantee their reusability and interoperability.
\end{abstract}

\section{Introduction}

Over the years Adaptive Hypermedia systems have evolved through three generations [4]: the pre-web generation, the web generation, and the new adaptive web generation. The latter -the current generation of AH- lumps together the need to explore actual tendencies of the web such as the open web and the semantic web [2]. These tendencies deal with the establishment of learning technology standards to define metadata to describe adaptation, user models, and learning resources.

Learning technology standards are agreements about the characteristics a learning element should have in order to be compatible, interchangeable and interoperable among learning systems. The use of standards ensures to universities and corporations around the world interoperability of their instructional technologies and learning objects [16].

Explicitly, standards help to assure the five "abilities" in learning systems [5]: interoperability, reusability, manageability, accessibility, and durability.

Although, semantic for personalization is not considered in current learning technology standards [7], the intention of our research work is to make use of them to describe Adaptive Educational Hypermedia Systems (AEHS). The goal is to ensure for the AEHS field the five "abilities" mentioned earlier.
Our approach is to design an open model for AEHS with the potential to fulfill a wide range of requirements, no matter the knowledge field, educational level, instructional design or learning style. Furthermore, the proposed model will give teachers the possibility of define their own adaptive rules.

In this paper we outline the open model we are designing. In section 2 , we describe the proposed model. In section 3, we expose conclusions and describe further work.

\section{The Open Model}

The initial architecture of the model (see Figure 1) has four models (or sub-models): the Learning Domain Model, the Student Model, the Adaptation Model, and the Interaction Model. The former interacts with a collection of definitions to describe tests, adaptive rules, learning designs, and learning styles.

Various learning technology specifications defined by IMS are used to describe the metadata of the elements. Namely, the IMS Learning Design (IMS LD) [10] is used to label the Learning Domain Model; the IMS Content Packaging (IMS CP) [9] is used to define the Interaction Model; and the IMS Meta-data (IMS LOM) [12] is used to annotate learning objects.

From the wide range of learning technology standards that are currently under development [1], we chose IMS LD mainly because it designs the learning process based on learning activities, it is open to any learning theory, it describes a pedagogical meta-model -based on EML [14]-, and it enables the possibility of integrating learning design to more advanced e-learning applications [15].

In the rest of this section we will introduce the components of the architecture. 
Berlanga, A., \& García-Peñalvo, F. J. (2004). A open model to define adaptive educational hypermedia systems based on learning technology specifications Proceedings of the 15th International Workshop on Database and Expert Systems Applications, 2004 (Zaragoza, Spain, 30 August - 3 September 2004) (pp. 198-202). USA: IEEE Computer Society Press.

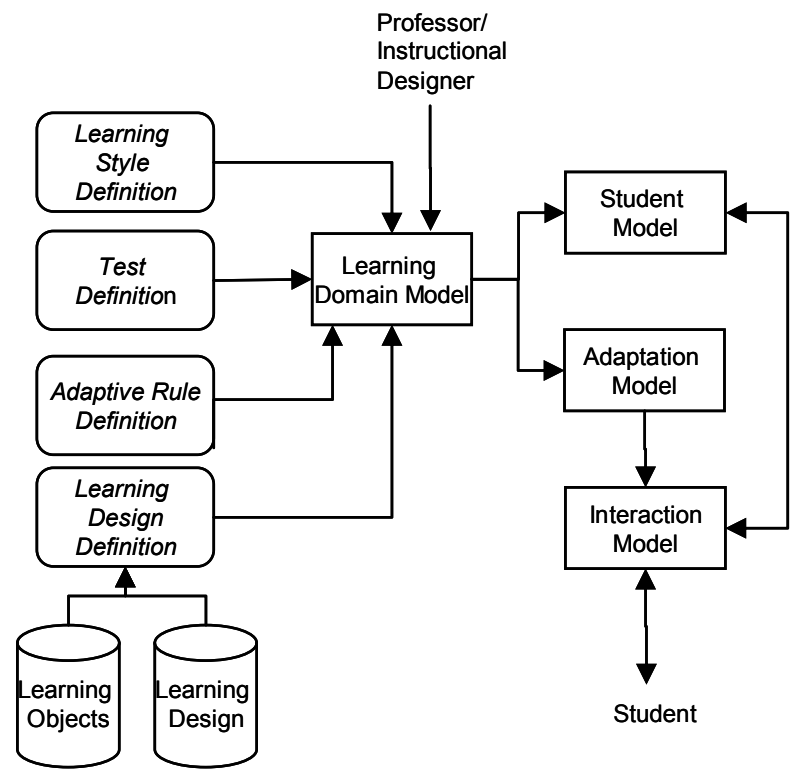

Figure 1. The initial architecture of the open model

\subsection{The Learning Domain Model}

The Learning Domain Model includes the learning style definition, the learning design definition, the test definition, and the adaptive rule definition.

2.1.1. Learning Style Definition. Learning styles try to establish indicators on how learners perceive, interpret, process and interact with learning environments. Considering these indicators it is possible to design learning materials and instructional designs most suitable to the way each learner learns.

Some researchers have proposed different learning style approaches. Two well known examples are the Felder and Silverman Learning Style Model [6] and the Kolb's Experiential Learning Theory [13].The former proposes ten dimensions. Two related to the way students receive the information (sensorial, intuition), and the other eight related to the way the information is processed (visual-verbal; inductive-deductive; activereflexive; sequential-global). Kolb's approach also takes into account the way the information is perceived (theorist and activist dimensions), and the way the information is processed (reflectors and pragmatist dimensions).

However, the idea of the proposed model is not to prescribe any learning style, but provide authors with a flexible structure where different learning style approaches can be described and used to characterize the learning styles of learners and activities.

Therefore, by means of the learning style definition the teacher specifies the learning styles approach that will be considered in the learning design. The definition of a learning style includes its name, description and dimensions. This information will create an element for every learning style definition that can be reused in other learning designs. Afterwards, these definitions will be used to depict the learners' learning style, the activities learning style as well as to define the learning style test.

2.1.2. The Learning Design Definition. The learning design definition describes the knowledge structure and the learning instructional design of the learning domain. The approach of the proposed model is based on learning activities. This is to say, instead of describing learning concepts, as some AEHS do, the learning experience is structured into learning activities.

As we have already mentioned, the definition of the learning design is guided by the IMS LD specification. Figure 2 shows the hierarchical order of its major elements (the asterisk * represents that an element may occur more than once). The teacher or instructional designer will use these elements to describe the learning design. This includes defining its objectives, prerequisites, components, learning method, and metadata.

The figure also shows the new element learning-style that we propose to include in the definition of learning activities and support activities. This inclusion will allow performing adaptation considering learning styles, because the learning style of the activities will be linked to the learning style of the student.

Although, the <learning-style> element is considered in neither IMS LD nor IMS Meta-Data, we suggest adding it in the IMS structure, instead of storing the learning style values in standardized metadata elements characterized for other purposes.

Further, it is important to be able to define that an activity can endorse more than one of the dimensions a learning style approach has. Consequently, the element learning-style will be added to the definition of learning activities to store what learning styles the activity supports and in what percentage. When the learning style of a learning activity or support activity is described, the learning style approaches created (see Learning Style Definition above) are defined as objects. These objects will be the base to describe the learning style of the activities. 
Berlanga, A., \& García-Peñalvo, F. J. (2004). A open model to define adaptive educational hypermedia systems based on learning technology specifications Proceedings of the 15th International Workshop on Database and Expert Systems Applications, 2004 (Zaragoza, Spain, 30 August - 3 September 2004) (pp. 198-202). USA: IEEE Computer Society Press.

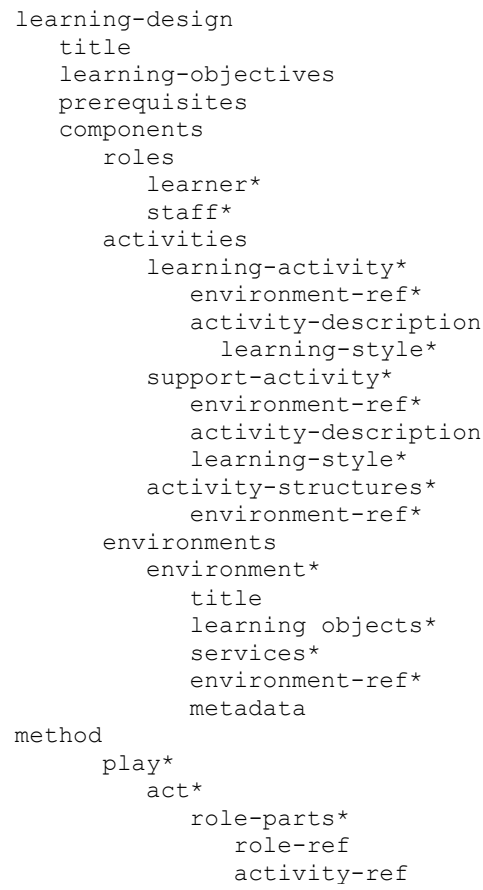

Figure 2. IMS LD main elements [10]

Figure 3 shows an example of the definition of the learning activity "Introduction to AH". Its learning style is defined following the Kolb's Theory as $70 \%$ theorist, $10 \%$ pragmatist, $10 \%$ activist, and $90 \%$ reflector.

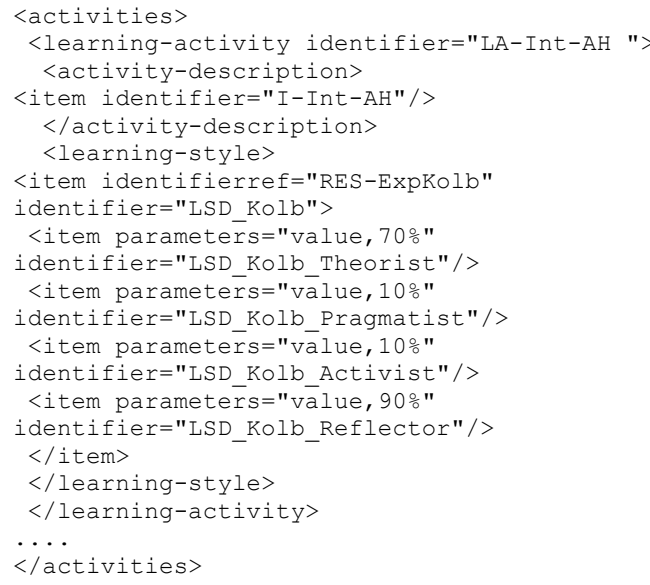

Figure 3. Learning style definition of an activity

The annotation uses the attribute "parameter" and the prefix LSD (Learning Style Definition) to define learning styles. This prefix is used to identify learning styles as those defined in the official IMS use of elements: LOB (learning-objectives), PRE (prerequisites), or LA (learning-activity).

2.1.3. Test Definition. The definition of tests describes the assessments that will be used in the learning design to measure the knowledge and learning style of the students. There are four types of tests: learning style, initial knowledge, current knowledge, and final knowledge.

The objective of the learning style test is to identify the learning style of the student. This type of test should be in accordance with a learning style definition created before, that will provide the dimensions to measure the learning style of the student. This test is defined by its name, description, linked learning style definition, and a set of questions that match a learning style definition dimension.

The objective of the initial knowledge test, current knowledge test, and final knowledge test is to measure the students' knowledge. The initial knowledge test and the final knowledge test have to be linked to a unit of learning ${ }^{1}$, while the current knowledge test has to be related to a learning activity or to an activity sequence.

The results of these tests set the values of the learning style, initial knowledge, current knowledge, and final knowledge of each student. These values are stored into the student model in order to use them to describe adaptive rules.

2.1.4. Adaptive Rule Definition. While in most cases the definition of adaptivity is pre-defined by the designers of AEHS, in the proposed model the objective is to give freedom to teachers and instructional designers to describe what characteristics and variables have to be considered to perform adaptivity. The goal is to provide a formalism to specify the rules that have to be considered to adequate the navigation paths and content to the students' characteristics.

The definition of adaptive rules is based on the description of adaptive statements that define conditions that will be taken into account to execute an action or actions. These conditions include IMS LD elements as prerequisites, learning objectives, learning activities, or activity sequences, as well as the learning styles of these elements. Moreover, they include characteristics of the student as his/her learning style, initial knowledge, current knowledge, final knowledge, or his/her interaction with the learning material. Actions can include sort elements, hide or show a learning element, or a menu with certain items.

\footnotetext{
${ }^{1}$ A unit of learning is modelled by including an IMS LD into a content package, preferably, IMS CP [9].
} 
Berlanga, A., \& García-Peñalvo, F. J. (2004). A open model to define adaptive educational hypermedia systems based on learning technology specifications Proceedings of the 15th International Workshop on Database and Expert Systems Applications, 2004 (Zaragoza, Spain, 30 August - 3 September 2004) (pp. 198-202). USA: IEEE Computer Society Press.

The description of adaptive statements includes a collection of sets (see Table 1), and follows the next predicates (BNF notation):

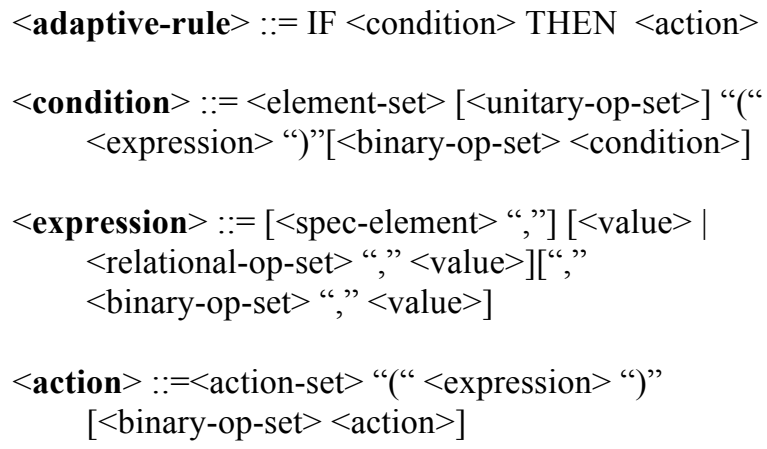

Table 1. Collection of sets to describe adaptive statements

\begin{tabular}{|c|c|c|}
\hline Set & Sub-set & Elements \\
\hline \multirow[t]{2}{*}{$\begin{array}{l}\text { element- } \\
\text { set }\end{array}$} & $\begin{array}{l}\text { learning-design- } \\
\text { structure }\end{array}$ & $\begin{array}{l}\text { Prerequisite; } \\
\text { Learning-objectives; } \\
\text { Learning-activities; } \\
\text { Activity-sequence; } \\
\text { Support-activity }\end{array}$ \\
\hline & student-element-set & Student \\
\hline \multirow{4}{*}{ data-set } & learning-style-set & Learning-style \\
\hline & student-data-set & $\begin{array}{l}\text { Initial-knowledge; } \\
\text { Current-knowledge; } \\
\text { Final-knowledge }\end{array}$ \\
\hline & attributes-data-set & $\begin{array}{l}\text { Completed; Visited; } \\
\text { Recommend; Sequence; } \\
\text { Selection }\end{array}$ \\
\hline & time-data-set & $\begin{array}{l}\text { Time-unit-of-learning-started; } \\
\text { Date-time-activity-started }\end{array}$ \\
\hline \multirow{2}{*}{$\begin{array}{l}\text { logic- } \\
\text { operators- } \\
\text { set }\end{array}$} & binary-op-set & And; Or \\
\hline & unitary-op-set & Not \\
\hline $\begin{array}{l}\text { relational- } \\
\text { operator- } \\
\text { set }\end{array}$ & relational-op-set & $\begin{array}{l}\text { Greater-than; Less-than; Equal; } \\
\text { Greater-or-equal-than; } \\
\text { Less-or-equal-than }\end{array}$ \\
\hline action-set & & $\begin{array}{l}\text { Show; Hide; Show-menu; } \\
\text { Hide-menu; Sort-ascending; } \\
\text { Sort-descending; } \\
\text { Number-to-select }\end{array}$ \\
\hline
\end{tabular}

\subsection{The Student Model}

The student model stores all the learner information that can be helpful to perform the adaptivity. It contains the learning style, initial knowledge, current knowledge, final knowledge, and information of the students' interaction with the content (e.g. visited learning activities).
The proposed model describes the student' learning style as a flexible combination of the different dimensions defined in a learning style approach. The learning styles that a student has (i.e. $\mathrm{s} /$ he has answered a learning style test) are stored in a vector defined as (BNF notation):

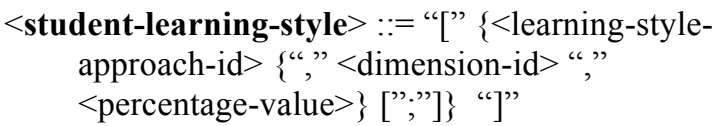

The idea behind this is to have a multi-layer student model where each layer represents a learning style approach. Every layer includes for each dimension of that approach, the percentage value that the student has of that dimension.

The information of the learning style could be stored in the element accessibility of the IMS Learner Information Package (IMS LIP) [11] due to this element describes information that includes cognitive preferences. Also, the sub-element preference could be used to store every layer of the student model. However, we decided not to do it this way because on one hand, IMS LIP is more directed to structure learner information from the management point of view rather than the personalization view [4], and on the other, an AEHS requires storing and managing the students behaviour and his/her interactions to execute the adaptivity. For example, in order to use the element visited of the attributes-data-set (see Table 1), it is compulsory for the AEHS to store the activities, prerequisites, learning objectives, and activity sequences the student visited. It is not possible, and it does not make sense, to collect this information in IMS LIP.

\subsection{The Adaptation Model}

The adaptation model integrates all the definitions of the learning domain model (learning design, test, learning style, adaptive rules), and generates automatically the IMS LD file that contains the learning design that will be presented to the students. Notice, that this model will translate the learning domain model and the adaptive rule definitions. The latter, will use the element $<$ method $>$ of IMS LD that defines the order of the activities, but also the learner properties and conditions that are useful to personalize learning.

\subsection{The Interaction Model}

The Interaction Model has two functions. The first function is to generate and deliver an adaptive unit of 
Berlanga, A., \& García-Peñalvo, F. J. (2004). A open model to define adaptive educational hypermedia systems based on learning technology specifications Proceedings of the 15th International Workshop on Database and Expert Systems Applications, 2004 (Zaragoza, Spain, 30 August - 3 September 2004) (pp. 198-202). USA: IEEE Computer Society Press.

learning for each student. A unit of learning includes a manifest, a learning design (the IMS LD file generated in the Adaptation Model), resources (the URI or URL references), possible (sub-) manifests and physical files [10]. IMS CP is used to annotate the file: this is the integration of IMS LD into IMS CP to create units of learning, and is the way of interchanging learning designs.

The other function is to track the behaviour of the student while s/he interacts with the learning material. Observation includes data about the learning activities the student visited, and the results of the four types of test. This information will update the student model.

\section{Conclusions and future work}

In this paper we presented an initial proposal to describe an open model to define AEHS. The model is directed to fulfil the requirements of teachers or instructional designers in such way that it will be possible to design learning environments for any knowledge field, educational level, instructional design or learning style. Furthermore, the model gives teachers the possibility to build their adaptive rules.

The proposed model is based on IMS specifications, thus, interoperability, reusability and exchangeability of learning components is a key factor. Moreover, adaptation rules can be used in learning designs created by others and vice versa.

We are extending the functionalities of the Hypermedia Composer (HyCo [7]), in order to use it as the learning design authoring tool [2]. Now, we are working on the definition of learning designs conform to IMS LD Level A. Afterwards, we will define adaptive statements, and analyzing how to describe them in the IMS LD element < conditions>.

\section{Acknowledgments}

We would like to thank the Adaptive Web Engineering Group (AWEG) of the University of Salamanca.

Adriana Berlanga thanks the Mexican Council of Science and Technology (CONACyT) for its support. This work is partly funded by the Government of Castile and Leon (projects SA017/02 and US05/03), and supported by the ODISEAME Project (EUMEDIS B7-4100/2000/2165-79 P546).

\section{References}

[1] A. Berlanga, E. Morales, F. García, F., Learning Technology Standards: Semantic Objects for Adaptive Learning Environments. In $2^{\text {nd }}$. Int. Conference on
Multimedia \& ICT in Education (m-ICTE2003) (Spain, December, 2003), pp. 860-864.

[2] A. Berlanga, F. Garcia, F., Towards Semantic Metadata for Learning Elements. In $5^{\text {th }}$ Int. Conference on Information Technology Based Higher Education \& Training (ITHET2004) (Turkey, 2004) IEEE.

[3] T. Berners-Lee, J. Hendler, O. Lassila, "The Semantic Web", Scientific American, 2001.

[4] P. Brusilovsky, W. Nejdl, "Adaptive Hypermedia and Adaptive Web". In Practical Handbook of Internet Computing, Munindar P. Singh (Ed.), Crc Press. 2003.

[5] elearning Consortium. Making sense of learning specifications and standards. The S3 Working Group. Masie Center. 2002.

[6] R.M., Felder, L.K. Silverman, "Learning and Teaching Styles in Engineering Education", Engineering Education, 1988, pp. 674-681.

[7] F. Garcia, A. Berlanga, M. Moreno, J. Garcia, J., Carabias, HyCo- An Authoring Tool to Create Semantic Learning Objects for Web-based E-Learning Systems. In Int. Conference on Web Engineering (ICWE2004) (Germany, 2004), Springer (to appear).

[8] N. Henze, From Web-Based Educational Systems to Education on the Web: On the Road to the Adaptive Web. In. $7^{\text {th }}$ Int. Conference on Knowledge-Based Intelligent Information \& Engineering Systems (KES 2003) (UK, September, 2003), Springer. pp. 297-303.

[9] IMS CP. IMS Content Packaging 1.1.3. 2003. http://www.imsglobal.org/content/packaging/index.cfm

[10] IMS LD. IMS Learning Design Specification 1.1. 2003. http://www.imsglobal.org/learningdesign/index.cfm

[11] IMS LIP. IMS Learner Information Package Specification 1.1.32003. http://www.imsglobal.org/profiles/index.cfm

[12] IMS LOM. IMS Learning Resource Metadata Specification 1.1.2. 2001. http://www.imsglobal.org/metadata/index.cfm

[13] D. Kolb, Experiential Learning: Experience as the Source of Learning and Development, Prentice-Hall, Inc., Englewood Cliffs, N.J., 1984.

[14] R. Koper, Modelling units of study from a pedagogical perspective. The pedagogical meta-model behind EML, 2001. http://eml.ou.nl/introduction/docs/pedmetamodel.pdf [February, 2003].

[15] P. van Rosmalen, F. Brouns, C. Tattersall, H. Vogten, J. van Bruggen, P. Sloep, R. Koper, Towards an open framework for adaptive, agent-supported e-learning, 2003. http://hdl.handle.net/1820/76 [February, 2003].

[16] D. Wiley, Connecting learning objects to instructional design theory, In The Instructional Use of Learning Objects, D. Wiley (Ed.): http://reusability.org/read/chapters/wiley.doc 2000. [March, 2004]. 